\title{
The Status of Laparoscopic Inguinal Hernia Surgery in Children: A Nationwide Assessment
}

\author{
Andrea Schmedding 1,*(D), Ahmad Alsweed ${ }^{2}$, Oliver Muensterer ${ }^{3}$ and Johannes Leonhardt $^{2}$ \\ 1 Department of Pediatric Surgery and Pediatric Urology, University Hospital Frankfurt, Goethe University \\ Frankfurt, D-60590 Frankfurt, Germany \\ 2 Department of Pediatric Surgery and Pediatric Urology, Klinikum Braunschweig gGmbH, \\ D-38126 Braunschweig, Germany; a.alsweed@klinikum-braunschweig.de (A.A.); \\ j.leonhardt@klinikum-braunschweig.de (J.L.) \\ 3 Department of Pediatric Surgery, Dr. von Hauner Children's Hospital, LMU Klinikum, \\ D-80337 Munich, Germany; oliver.muensterer@med.uni-muenchen.de \\ * Correspondence: andrea.schmedding@kgu.de
}

Citation: Schmedding, A.; Alsweed, A.; Muensterer, O.; Leonhardt, J. The Status of Laparoscopic Inguinal Hernia Surgery in Children: A Nationwide Assessment. Children 2022, 9, 348. https://doi.org/ 10.3390 /children 9030348 Academic Editors: Robert Bergholz and Thomas Franz Krebs

Received: 10 February 2022

Accepted: 1 March 2022

Published: 3 March 2022

Publisher's Note: MDPI stays neutral with regard to jurisdictional claims in published maps and institutional affiliations.

Copyright: (C) 2022 by the authors. Licensee MDPI, Basel, Switzerland. This article is an open access article distributed under the terms and conditions of the Creative Commons Attribution (CC BY) license (https:// creativecommons.org/licenses/by/ $4.0 /)$.

\begin{abstract}
Inguinal hernia repair (IHR) is a common procedure in childhood. Laparoscopic IHR has been evolving for the last three decades. Although clear advantages have been shown, adaptation in Germany has been slow. We aim to study the current status of pediatric laparoscopic IHR. A survey was sent to all 89 pediatric surgical departments in Germany on current practices and preferences of open versus laparoscopic IHR. Two nationwide databases of administrative claims data from 2019 were analyzed and correlated with responses from the survey. A total of $56 \%$ of the pediatric surgical departments supplied data through the quality reports. The recall of our survey was $58 \%$ of all pediatric surgery departments. According to the pooled data, laparoscopic IHR was performed in $8.2 \%$ of all inpatients treated. Laparoscopic IHR was considered a training procedure in $48 \%$ of the departments. Five different laparoscopic techniques were described (most commonly percutaneous closure of the hernia under laparoscopic vision). The choice between open and laparoscopic IHR was mainly determined by the child's age. Currently, only a minority of German children undergo inguinal hernia repair by laparoscopy. More training opportunities in the form of hands-on and video workshops may lead to more widespread employment of the laparoscopic technique.
\end{abstract}

Keywords: inguinal hernia; child; laparoscopic inguinal hernia repair; pediatric surgery; minimal invasive

\section{Introduction}

Inguinal hernia repair (IHR) is the most common surgical procedure in childhood. The incidence of inguinal hernia under the age of 18 years is estimated to be between 0.8 and $4.4 \%$ [1]. It is much more common in males (male to female ratio is 5 to 1 ) [2]. In males, the peak incidence is in the first year, whereas in girls it is at around 5 years of life [3].

Most of the inguinal hernias in children are indirect [2]. Pediatric inguinal hernia repair usually comprises dissection of the hernia sac at the inner inguinal ring followed by high ligation. Open IHR is an extra-abdominal procedure with a high success rate and few complications. It is still considered the most commonly performed approach in children.

Laparoscopic IHR has evolved since its introduction in the early 1990s [1]. Since then, different techniques have been described, including a transabdominal three-port technique with suturing the neck of the hernia sack [4] and single-port laparoscopic percutaneous extraperitoneal closure assisted by optical forceps [5].

Clear advantages for laparoscopic inguinal hernia repair have been demonstrated in terms of shorter operative times for bilateral hernias [6], a reduction in metachronous hernia development [7] and the opportunity to explore and proactively repair a contralateral hernia [8]. Total postoperative complications have been reported less in laparoscopic IHR [9], as well as a decreased risk of postoperative iatrogenic ascending testis. The 
main disadvantage is an increased risk of wound infection [8]. Moreover, a recent metaanalysis found no difference regarding overall mean operative time, postoperative pain and recurrence rate [10].

In an international survey from 2012 with respondents from 46 countries, the preferred approach for inguinal hernia was open in $83 \%$ and laparoscopic in $4 \%$ [11]. In a recent survey from Denmark, $14 \%$ of respondents considered laparoscopic IHR in children below two years of age, while $34 \%$ considered it in children older than twelve years of age [12].

Although many studies have been published comparing laparoscopic and open IHR, it is unclear how and how often laparoscopic technique is used in Germany on a national level. Our goal for this study was therefore to evaluate if laparoscopic inguinal hernia repair remained a niche technique performed by a select group of highly specialized pediatric surgeons or if it had evolved into an accepted mainstream therapy.

Germany is a country with decentralized pediatric surgical care [13], comprising of 89 departments, 42 small units and 100 private practices distributed throughout the country [14]. Currently there are more than 700 active pediatric surgeons in practice. Furthermore, IHR in children is performed by pediatric surgeons and surgeons of other specialties, such as urologists and general surgeons. Inguinal hernia repairs are either performed in hospitals or private practices. They are mainly performed by pediatric surgeons. Hospitals perform these procedures with a hospital admission or as an outpatient procedure.

The goal of this study was to analyze the contemporary distribution and preference of open and laparoscopic inguinal hernia repair in German pediatric surgical practice.

\section{Materials and Methods}

The study consisted of three parts: Part 1-A survey among all pediatric surgical departments; Part 2-The analysis of the national database on administrative claims data of all hospital admissions for Germany, provided by the Institute for the Remuneration System in Hospitals (InEK) [15]; Part 3-The analysis of the quality reports of the hospitals for Germany, published by the joined federal committee (G-BA) [16]. All data are obtained from the year 2019.

\subsection{Survey among All Pediatric Surgical Departments of Germany}

An anonymized online survey about the surgical concept of inguinal hernia repair (IHR) was sent to all department heads of the 89 pediatric surgical departments in Germany in 2019. The list of all pediatric surgical departments of Germany was obtained from the homepage of the German Society of Pediatric Surgery (DGKCH) [14]. The survey consisted of the following main questions:

- How many patients do you operate on with inguinal hernia per year?

- What technique is used for inguinal hernia repair?

- What kind of technique do you use for laparoscopic hernia repair?

- What is the reason to choose a specific technique?

- What kind of technique do you use for relapse?

- What size of instruments do you use?

- Who performs the surgery?

- Do you perform this surgery in incarcerated inguinal hernia?

The complete survey is available in Table 1.

Table 1. Answers of the survey about laparoscopic inguinal hernia repair.

\begin{tabular}{lccc}
\hline Question & Respondents & Answers & Percentage \\
\hline What is your clinical setting? & & & \\
· Hospital department & 52 & 49 & $94.2 \%$ \\
· Private practice with hospital beds & & 3 & $5.8 \%$ \\
\hline
\end{tabular}


Table 1. Cont.

\begin{tabular}{|c|c|c|c|}
\hline Question & Respondents & Answers & Percentage \\
\hline $\begin{array}{l}\text { Do you operate on children }(0-14 \text { years old }) \\
\text { with indirect inguinal hernia in your } \\
\text { department? } \\
\text { · Yes } \\
\text { - No }\end{array}$ & 48 & $\begin{array}{c}47 \\
1 \\
\end{array}$ & $\begin{array}{c}97.9 \% \\
2.1 \% \\
\end{array}$ \\
\hline $\begin{array}{l}\text { How many patients with inguinal hernia do } \\
\text { you operate on per year? } \\
\cdot<50 \\
\cdot<100 \\
\cdot<150 \\
\cdot \text { More than } 150\end{array}$ & 51 & $\begin{array}{c}6 \\
12 \\
17 \\
16\end{array}$ & $\begin{array}{l}11.8 \% \\
23.5 \% \\
33.3 \% \\
31.4 \%\end{array}$ \\
\hline $\begin{array}{l}\text { What kind of technique do you use for inguinal } \\
\text { hernia repair? } \\
\text {. Open surgery only } \\
\text {. Laparoscopic surgery only } \\
\text {. Both techniques }\end{array}$ & 51 & $\begin{array}{c}24 \\
3 \\
24\end{array}$ & $\begin{array}{l}47.1 \% \\
5.9 \% \\
47.1 \%\end{array}$ \\
\hline $\begin{array}{l}\text { Which technique do you perform in } \\
\text { laparoscopic inguinal hernia repair? } \\
\text { - Percutaneous closure ( } 1 \text { trocar) } \\
\text { - Intracorporal suture with cut of the } \\
\text { peritoneum ( } 2-3 \text { trocar) } \\
\text { - Intracorporal technique with sling ( } 2-3 \text { trocar) } \\
\text { - Intracorporal suture without cut ( } 2-3 \text { trocar }) \\
\text { - Other technique }\end{array}$ & 30 & $\begin{array}{l}10 \\
9 \\
2 \\
8 \\
4\end{array}$ & $\begin{array}{c}33.3 \% \\
30.0 \% \\
6.7 \% \\
26.7 \% \\
13.3 \%\end{array}$ \\
\hline $\begin{array}{l}\text { Indication for the kind of surgical technique of } \\
\text { laparoscopic inguinal hernia repair. } \\
\cdot \text { Age of the child } \\
\cdot \text { Sex of the child } \\
\text {. Pre-existing condition of the child } \\
\text { - Preference of the surgeon } \\
\text { - Request of parents } \\
\text { - Other }\end{array}$ & 31 & $\begin{array}{l}16 \\
12 \\
15 \\
10 \\
15 \\
8\end{array}$ & $\begin{array}{l}51.6 \% \\
38.7 \% \\
48.4 \% \\
32.3 \% \\
48.4 \% \\
25.8 \%\end{array}$ \\
\hline $\begin{array}{l}\text { Do you perform laparoscopic inguinal hernia } \\
\text { repair in incarcerated hernia? } \\
\text { - Yes } \\
\text { - No }\end{array}$ & 30 & $\begin{array}{c}6 \\
24\end{array}$ & $\begin{array}{l}20.0 \% \\
80.0 \%\end{array}$ \\
\hline $\begin{array}{l}\text { What kind of technique do you use in recurrent } \\
\text { hernia? } \\
\text { - Always open surgery } \\
\text { - Always minimal-invasive surgery } \\
\text {. Change of technique (dependent on the } \\
\text { method used before) }\end{array}$ & 46 & $\begin{array}{c}27 \\
5 \\
13\end{array}$ & $\begin{array}{l}58.7 \% \\
10.9 \% \\
28.3 \%\end{array}$ \\
\hline $\begin{array}{l}\text { What kind of instruments do you use for } \\
\text { minimal-invasive surgery? } \\
.5 \mathrm{~mm} \text { instruments } \\
.3 \mathrm{~mm} \text { instruments } \\
.2 \mathrm{~mm} \text { instruments }\end{array}$ & 30 & $\begin{array}{c}10 \\
14 \\
6\end{array}$ & $\begin{array}{l}33.3 \% \\
46.7 \% \\
20.0 \%\end{array}$ \\
\hline $\begin{array}{l}\text { What is your setting for minimal-invasive } \\
\text { surgery? } \\
\text { - Outpatient procedure } \\
\text { - Inpatient procedure } \\
\text {. Inpatient and outpatient procedure }\end{array}$ & 26 & $\begin{array}{c}6 \\
13 \\
7\end{array}$ & $\begin{array}{l}23.1 \% \\
50.0 \% \\
26.9 \%\end{array}$ \\
\hline
\end{tabular}


Table 1. Cont.

\begin{tabular}{lccc}
\hline Question & Respondents & Answers & Percentage \\
\hline $\begin{array}{l}\text { Who is performing the laparoscopic inguinal } \\
\text { hernia repair? }\end{array}$ & & & \\
· Fully trained pediatric surgeons only & 31 & 16 & $51.6 \%$ \\
Fully trained pediatric surgeons and trainees & & 14 & $45.2 \%$ \\
- Trainees only & 1 & $3.2 \%$ \\
\hline
\end{tabular}

\subsection{Analysis of the National Database on Administrative Claims Data for Hospital Patients} of Germany

Cumulative statistics on all hospital admissions were mined from the InEK (Institut für das Entgeldsystem im Krankenhaus, the German Institute for the Renumeration System of hospitals) [13]. These data contain all diagnoses and procedures of patients admitted to a German hospital, regarding age groups of the patients. Coding of the diagnoses is carried out with the International Classification of Diseases (ICD)-10 Code, German modification [17]. Procedures are coded using the German procedure classification (OPS) [18].

The data do not provide information on the specialty of the provider (e.g., pediatric surgeon, general surgeon, urologist) who performed the procedure.

This national database was analyzed for the year 2019. Data on all patients with the OPS 5-530 for IHR were extracted. Those patients with the code 5-530.02 for orchidofuniculysis and IHR were excluded.

\subsection{Analysis of the Quality Reports of Germany}

The yearly published quality reports contain the procedures performed for hospitaladmitted patients and those treated on an outpatient basis for each hospital department. Some hospitals accumulate these data, e.g., on pediatric surgical patients together with general surgical patients. Only pediatric surgical datasets which were not accumulated with data from adult surgery were used in this study.

The quality reports of the hospitals of 2019 were analyzed regarding numbers of procedures of open and laparoscopic IHR performed in a pediatric surgical hospital department. For data protection rules, case frequencies below 4 were pooled and counted as one.

\section{Results}

\subsection{Survey among All Pediatric Surgical Departments of Germany}

Fifty-one of the 89 (58.4\% recall) departments answered the questionnaire. Of these, $47.1 \%$ exclusively performed open IHR, $5.9 \%$ performed only laparoscopic IHR and both methods were performed in $47.1 \%$ of departments (Table 1 ).

Laparoscopic IHR was performed by fully trained specialists only in $51.6 \%$ of respondents, whereas it was considered a training procedure in $48.4 \%$ of the participating institutions. The main technique was percutaneous closure of the hernia under laparoscopic vision (33\%). Intracorporal techniques using up to three trocars were employed in $63 \%$ of the queried departments. The choice between open and laparoscopic IHR was mainly determined by the age of the child (52\%). Almost half of the departments used $3 \mathrm{~mm}$ instruments for the procedure, the others used $5 \mathrm{~mm}$ or $2 \mathrm{~mm}$ instruments. Of respondents, $20 \%$ used laparoscopic IHR in incarcerated hernia, 11\% used it as the only technique for recurrent inguinal hernia (Table 1).

\subsection{Analysis of the National Database on Administrative Claims Data for Hospital Patients of Germany}

In 2019, 175,824 patients underwent inpatient IHR in Germany, 9718 (5.5\%) of which were less than 18 years old. According to the national database, a total of 801 pediatric inguinal hernia repairs (under 18 years of age) were performed laparoscopically in the study interval. 
Of the 9718 children with IHR, 18\% were females, with a higher proportion of females $(38 \%)$ in laparoscopic IHR. A total of $74 \%$ of all children with IHR were less than two years of age, compared to only $33 \%$ of the children with laparoscopic IHR (Table 2). The comparison of the age groups of the children with open and laparoscopic IHR is presented in Figure 1.

Table 2. Age, gender and diagnoses of children with open and laparoscopic inguinal hernia repair.

\begin{tabular}{lcccccc}
\hline & \multicolumn{2}{c}{ All } & \multicolumn{2}{c}{ Open } & \multicolumn{2}{c}{ Laparoscopic } \\
\hline all & 9718 & & 8926 & $91.9 \%$ & 801 & $8.2 \%$ \\
\hline males & 7968 & $82.0 \%$ & 7363 & $84.0 \%$ & 497 & $62.0 \%$ \\
\hline females & 1750 & $18.0 \%$ & 1402 & $16.0 \%$ & 304 & $38.0 \%$ \\
\hline $0-28$ days & 1067 & $11.0 \%$ & 1046 & $11.7 \%$ & 21 & $2.6 \%$ \\
\hline 29 days-1 year & 4757 & $49.0 \%$ & 4602 & $51.6 \%$ & 161 & $20.1 \%$ \\
\hline $1-2$ years & 1343 & $13.8 \%$ & 1263 & $14.1 \%$ & 81 & $10.1 \%$ \\
\hline 3-5 years & 1192 & $12.3 \%$ & 1037 & $11.6 \%$ & 156 & $19.5 \%$ \\
\hline 6-10 years & 578 & $5.9 \%$ & 493 & $5.5 \%$ & 85 & $10.6 \%$ \\
\hline $11-15$ years & 424 & $4.4 \%$ & 336 & $3.8 \%$ & 89 & $11.1 \%$ \\
\hline $16-17$ years & 357 & $3.7 \%$ & 149 & $1.7 \%$ & 208 & $26.0 \%$ \\
\hline Inguinal hernia as main diagnosis & 7359 & $75.7 \%$ & 6643 & $68.4 \%$ & 718 & $89.6 \%$ \\
\hline Recurrent inguinal hernia & 225 & $2.3 \%$ & 174 & $1.9 \%$ & 47 & $5.9 \%$ \\
\hline Incarcerated inguinal hernia & 1089 & $11.2 \%$ & 1028 & $11.5 \%$ & 45 & $5.6 \%$ \\
\hline Bilateral inguinal hernia & 1175 & $12.1 \%$ & 986 & $11.0 \%$ & 190 & $23.7 \%$ \\
\hline
\end{tabular}

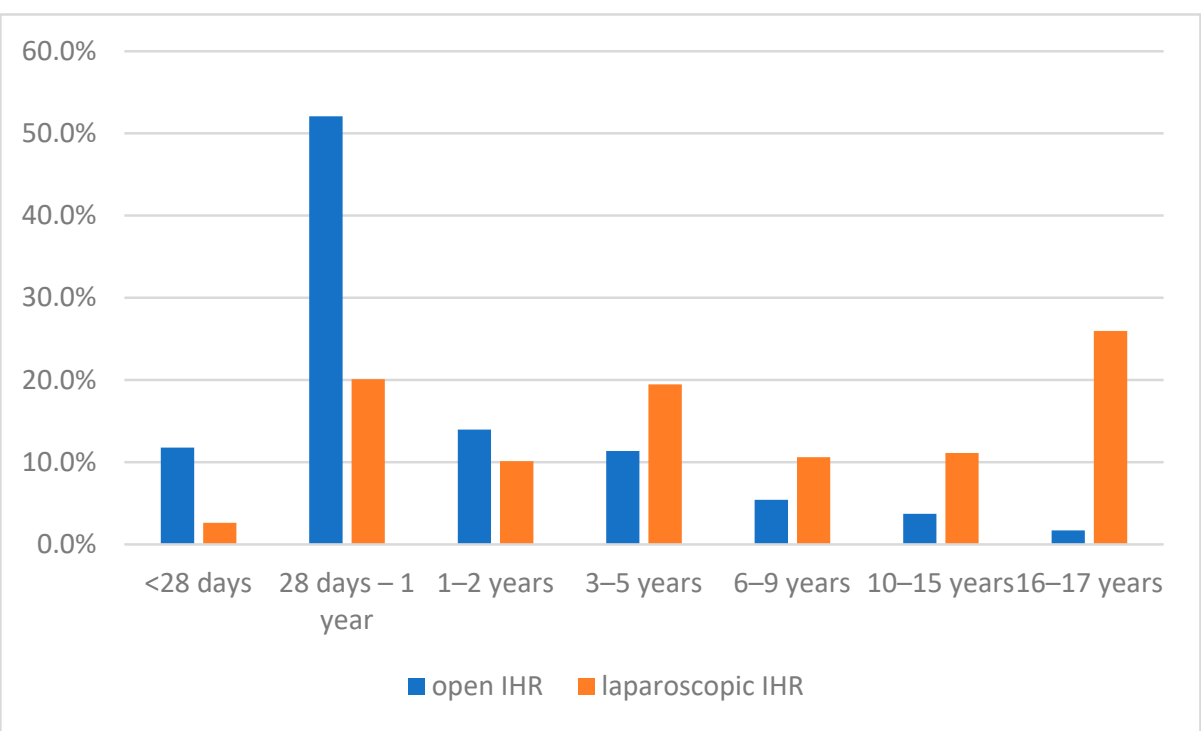

Figure 1. Distribution of age groups of children with open $(n=8926)$ and laparoscopic $(n=801)$ inguinal hernia repair.

Of the patients with laparoscopic IHR, 90\% had a main ICD code for inguinal hernia, meaning that they were admitted for IHR as the main reason for admission. Nearly $6 \%$ of them had a main ICD code for recurrent hernia, $6 \%$ had a code for incarcerated hernia and $24 \%$ had a code of bilateral inguinal hernia. Of the patients with open IHR, only $68 \%$ had a main code for inguinal hernia; the others had a hospital admission for other reasons. Of the patients admitted for open IHR, 3\% had an ICD code for recurrent hernia, 12\% for incarcerated hernia and $11 \%$ for bilateral hernia. 
For the technique of laparoscopic IHR, the OPS codes differentiate between those with the use of any material and without. Using an OPS code with the use of any material requires a secondary code for the kind of material. Laparoscopic IHR with the use of any material was documented in $37 \%$ of the patients under the age of ten and $84 \%$ of the patients between ten and 17 years of age. Nonresorbable materials were documented in $33 \%$, compared to (partial) resorbable materials in $23 \%$. The code for the kind of used materials was not provided in $44 \%$ of all children. (Table 3 )

Table 3. Technique of laparoscopic inguinal hernia repair (IHR).

\begin{tabular}{|c|c|c|c|c|c|c|}
\hline \multirow{2}{*}{$\begin{array}{l}\text { Age Group } \\
\text { IHR without the use of any material }\end{array}$} & \multicolumn{2}{|c|}{ All } & \multicolumn{2}{|c|}{$0-9$} & \multicolumn{2}{|c|}{ 10-17 } \\
\hline & 364 & $45.3 \%$ & 317 & $62.9 \%$ & 47 & $15.6 \%$ \\
\hline - with partial resection of hernia sac & 68 & $8.5 \%$ & 61 & $12.1 \%$ & 7 & $2.3 \%$ \\
\hline - other & 296 & $36.8 \%$ & 256 & $50.8 \%$ & 40 & $13.3 \%$ \\
\hline IHR with the use of any material & 440 & $54.7 \%$ & 187 & $37.1 \%$ & 253 & $84.3 \%$ \\
\hline - $\quad$ transperitoneal & 354 & $44.0 \%$ & 186 & $36.9 \%$ & 168 & $56.0 \%$ \\
\hline - extraperitoneal & 86 & $10.7 \%$ & 1 & $0.2 \%$ & 85 & $28.3 \%$ \\
\hline \multicolumn{7}{|l|}{ Material } \\
\hline - $\quad$ not coded & 194 & $44.1 \%$ & 155 & $82.9 \%$ & 39 & $15.4 \%$ \\
\hline - $\quad$ (partial) resorbable & 103 & $23.4 \%$ & 28 & $15.0 \%$ & 75 & $29.6 \%$ \\
\hline - $\quad$ nonresorbable & 143 & $32.5 \%$ & 4 & $2.1 \%$ & 139 & $54.9 \%$ \\
\hline
\end{tabular}

\subsection{Analysis of the Quality Reports of Germany}

A total of 70 of the $89(79 \%)$ pediatric surgical departments, four of the 42 small units $(10 \%)$ and four of the 100 private practices $(4 \%)$, who also have access to hospital beds, had public available data in their quality reports. University hospitals were represented in 23 of the 78 units $(30 \%)$.

Forty of the 78 units (51\%) and twelve of the 23 university hospitals (52\%) performed laparoscopic IHR (Figure 2). The mean number for IHR in 2019 was 102 for all hospitals, 106 for university hospitals and 93 for non-university hospitals. The mean number for laparoscopic IHR was 12 for all hospitals, 19 for university hospitals and 9 for non-university hospitals. A total of $65 \%$ of all laparoscopic IHRs were performed by six hospitals, two of which were university hospitals, which performed $36 \%$ of those documented in the quality reports. The distribution of laparoscopic IHR regarding inpatient and outpatient procedures is provided in Table 4.

Table 4. Numbers of procedures of laparoscopic inguinal hernia repair (IHR) per pediatric surgical unit documented in the quality reports.

\begin{tabular}{lccccc}
\hline & \multicolumn{2}{c}{ Hospitals } & \multicolumn{3}{c}{ Number of Laparoscopic IHR } \\
\hline & Number & $\%$ & Median & 1st Quartile & 3rd Quartile \\
\hline All hospitals & 40 & & 4 & 1 & 16.5 \\
\hline - inpatient & 37 & $92.5 \%$ & 3 & 1 & 15 \\
\hline - outpatient & 13 & $32.5 \%$ & 1 & 1 & 13 \\
\hline University hospitals & 11 & & 9.5 & 1.8 & 20 \\
\hline - inpatient & 9 & $81.8 \%$ & 8 & 2.5 & 19 \\
\hline - outpatient & 5 & $45.5 \%$ & 1 & 1 & 17 \\
\hline Non-university hospitals & 29 & & 3 & 1 & 13 \\
\hline - inpatient & 28 & $96.6 \%$ & 3 & 1 & 11.5 \\
\hline - outpatient & 7 & $24.1 \%$ & 1 & 1 & 1 \\
\hline
\end{tabular}




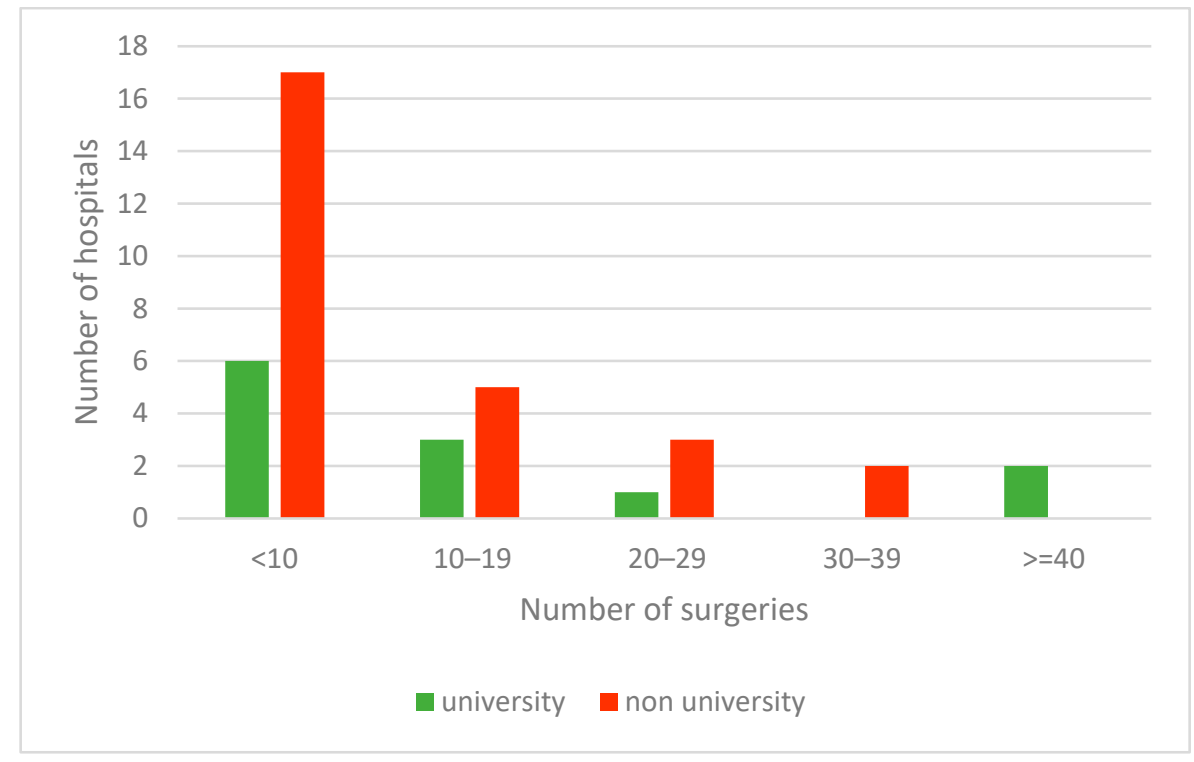

Figure 2. Number of procedures of laparoscopic inguinal hernia repair of university and nonuniversity hospitals in 2019.

As in the InEK data, $48 \%$ of the codes used for laparoscopic IHR were codes with the use of any material; $52 \%$ were without. The corresponding codes for used material cannot be analyzed from these data.

\section{Discussion}

Our study gives an up-to-date account of the current practice of pediatric inguinal hernia in Germany. Consistent with previous studies [2], 82\% of the children in our study were male and $86 \%$ were less than six years old.

We showed that open IHR with high ligation of the hernia sac is still the gold-standard technique in Germany. Laparoscopic IHR in children plays a minor role. However, there seems to be a trend towards more prevalent utilization of the laparoscopic technique. In a study of German administrative claims data for the years 2005-2017, laparoscopic IHR was used in boys for between $1 \%$ and $3 \%$ of cases and in girls for between $2 \%$ and $14 \%$ of cases for the different age groups [19]. While our analysis showed that the open technique is still used in more than $90 \%$ of all patients in 2019, the percentage of laparoscopic IHR increased to $6 \%$ of boys and $17 \%$ of girls. Nevertheless, these numbers are still lower than in a study from Japan with 26\% of laparoscopic hernia repair in a cohort from 2010-2016 [20] and of a US study with data from 2009-2014 with a rate of 13\% laparoscopic IHR [21].

Although a recent meta-analysis showed no overall superiority for laparoscopic IHR [22], some advantages are described. Laparoscopic IHR is seen advantageous for special conditions such as bilateral hernia [6,7] and incarcerated hernia [23,24]. In our series, the percentage of bilateral hernia in laparoscopic IHR was $24 \%$ and in open IHR it was $11 \%$. For incarcerated inguinal hernia, laparoscopic IHR is regarded as easier to perform in literature. [23,24] In contrast to this, in our study only $6 \%$ of the laparoscopic IHR was for incarcerated hernia, whereas $12 \%$ of the open IHR was for incarcerated hernia.

Over the last decades, different methods for laparoscopic IHR have been described, including transperitoneal and extraperitoneal techniques. $[1,25,26]$ In our survey $33 \%$ of pediatric surgeons prefer transperitoneal technique using only one trocar for the camera. Four different procedures with 2-3 trocars for intracorporal suturing with or without opening the peritoneum are performed in the study period in Germany. The use of mesh was not mentioned as a technique by pediatric surgeons. In contrast to this, the use of the code for IHR with any material is used by pediatric surgical departments, as seen in the quality reports. The analysis of the IHR in the InEK data leads to the conclusion that this 
is a coding problem, as in younger children no obligatory code for the kind of material is provided.

In the group of adolescents, $84 \%$ had surgery with the use of any material, and in $85 \%$ the additional obligatory OPS code for the material was given. As IHR in Germany is performed by pediatric and general surgeons, these numbers indicate that adolescents are operated on more often by general surgeons, since pediatric surgeons did not state this technique in our survey. This is in line with a survey among pediatric and general surgeons where technique was determined mostly by the preference of the surgeon, with general surgeons using mesh more often [27]. Regarding the medical impact of the mesh repair, a recent review of adolescent IHR concluded that there is no superiority of either method regarding recurrence rate. The mesh repair seemed to have a higher rate of chronic postoperative pain [28]. Further research regarding this topic should address children operated by general surgeons.

Laparoscopic IHR is not distributed equally in pediatric surgery in Germany, as $47 \%$ of the respondents of our survey and $49 \%$ of the pediatric surgical units with quality reports offered open surgery only. University medicine is generally seen as a promoter for innovation. However, in our study the percentage of university hospitals performing laparoscopic IHR was not higher than the percentage of non-university hospitals. Two university hospitals performed $36 \%$ of all laparoscopic procedures documented in the quality reports, indicating that these academic departments are protagonists for laparoscopic IHR.

Open IHR is an operation that is taught to the pediatric surgical trainee under direct supervision in the operation room. It is one of the first surgeries a trainee performs [29]. Laparoscopic IHR needs different training, but skills could be acquired within 12 months according to a Japanese study [30]. In our survey, laparoscopic IHR was performed in $48 \%$ of the hospitals by trainees.

Our study has several drawbacks. Most importantly, procedures of private practices are not entered into national or insurance databases, and quality reports do not distinguish between procedures for adults and underaged people. Therefore, our study focused on inguinal hernia repair performed in hospitals with pediatric surgery units.

We also have to address the above-mentioned coding problem. In our survey, pediatric surgeons did not use mesh, but in the data from InEK mesh repair was coded in $54.7 \%$ of the patients. When using a code for IHR with the use of any material, a secondary code has to be provided specifying the kind or material. This code was not given for $44.1 \%$ of the patients. In the group under the age of ten years, it was lacking in $82.9 \%$ of the patients. This is an indication of a coding problem, which is in line with the data of the quality reports, where $48.3 \%$ of the OPS codes performed by pediatric surgeons were for IHR with the use of any material, which is in contrast to the technical details provided in our survey.

\section{Conclusions}

Currently, only a minority of German children undergo inguinal hernia repair by laparoscopy. More training opportunities in the form of hands-on and video workshops may lead to more widespread employment of the laparoscopic technique.

Author Contributions: Conceptualization, all authors; methodology, A.S. and J.L.; writing—original draft preparation, A.S.; writing - review and editing, all authors. All authors have read and agreed to the published version of the manuscript.

Funding: This research received no external funding.

Institutional Review Board Statement: The survey among pediatric surgeons was performed anonymously and therefore did not need Institutional Review Board approval. This was confirmed by the local ethic committee. In Germany, the utilization of administrative claims data for scientific research is regulated by the Code of Social Law. The study uses only pooled data that never involved patients directly. The analysis of secondary data did not need Institutional Review Board approval as stated in the guidelines for Good Practice of Secondary Data Analysis (GPS) and was confirmed by the local ethic committee. 
Informed Consent Statement: Not applicable.

Data Availability Statement: Data of the used quality reports of the hospitals of Germany can be found at https:/ /www.g-ba-qualitaetsberichte.de/\#/search, accessed 31 January 2022, data of the Remuneration System in Hospitals (InEK) can be retrieved at https:/ / www.g-drg.de/, accessed 31 January 2022. All data of the survey are published in the article.

Acknowledgments: We would like to thank all department heads of the pediatric surgical departments who took part in this survey.

Conflicts of Interest: The authors declare no conflict of interest.

\section{References}

1. Esposito, C.; Escolino, M.; Turrà, F.; Roberti, A.; Cerulo, M.; Farina, A.; Caiazzo, S.; Cortese, G.; Servillo, G.; Settimi, A. Current Concepts in the Management of Inguinal Hernia and Hydrocele in Pediatric Patients in Laparoscopic Era. Semin. Pediatr. Surg. 2016, 25, 232-240. [CrossRef] [PubMed]

2. Ein, S.H.; Njere, I.; Ein, A. Six Thousand Three Hundred Sixty-One Pediatric Inguinal Hernias: A 35-Year Review. J. Pediatr. Surg. 2006, 41, 980-986. [CrossRef] [PubMed]

3. Chang, S.-J.; Chen, J.Y.-C.; Hsu, C.-K.; Chuang, F.-C.; Yang, S.S.-D. The Incidence of Inguinal Hernia and Associated Risk Factors of Incarceration in Pediatric Inguinal Hernia: A Nation-Wide Longitudinal Population-Based Study. Hernia 2016, 20 , 559-563. [CrossRef] [PubMed]

4. Raveenthiran, V.; Agarwal, P. Choice of Repairing Inguinal Hernia in Children: Open Versus Laparoscopy. Indian J. Pediatr. 2017, 84, 555-563. [CrossRef]

5. Yilmaz, E.; Afsarlar, C.E.; Senel, E.; Cavusoglu, Y.H.; Karaman, I.; Karaman, A.; Ozguner, I.F. A Novel Technique for Laparoscopic Inguinal Hernia Repair in Children: Single-Port Laparoscopic Percutaneous Extraperitoneal Closure Assisted by an Optical Forceps. Pediatr. Surg. Int. 2015, 31, 639-646. [CrossRef]

6. Davies, D.A.; Rideout, D.A.; Clarke, S.A. The International Pediatric Endosurgery Group Evidence-Based Guideline on Minimal Access Approaches to the Operative Management of Inguinal Hernia in Children. J. Laparoendosc. Adv. Surg. Tech. A 2020, 30, 221-227. [CrossRef]

7. Alzahem, A. Laparoscopic versus Open Inguinal Herniotomy in Infants and Children: A Meta-Analysis. Pediatr. Surg. Int. 2011, 27, 605-612. [CrossRef]

8. Kantor, N.; Travis, N.; Wayne, C.; Nasr, A. Laparoscopic versus Open Inguinal Hernia Repair in Children: Which Is the True Gold-Standard? A Systematic Review and Meta-Analysis. Pediatr. Surg. Int. 2019, 35, 1013-1026. [CrossRef]

9. Feng, S.; Zhao, L.; Liao, Z.; Chen, X. Open Versus Laparoscopic Inguinal Herniotomy in Children: A Systematic Review and Meta-Analysis Focusing on Postoperative Complications. Surg. Laparosc. Endosc. Percutan. Tech. 2015, 25, 275-280. [CrossRef]

10. Mahmood, B.; Christoffersen, M.; Miserez, M.; Bisgaard, T. Laparoscopic or Open Paediatric Inguinal Hernia Repair-A Systematic Review. Dan. Med. J. 2020, 67, A12190725.

11. Zani, A.; Eaton, S.; Hoellwarth, M.E.; Puri, P.; Tovar, J.; Fasching, G.; Bagolan, P.; Lukac, M.; Wijnen, R.; Kuebler, J.F.; et al. International Survey on the Management of Esophageal Atresia. Eur. J. Pediatr. Surg. 2014, 24, 3-8. [CrossRef] [PubMed]

12. Olesen, C.S.; Andersen, K.; Öberg, S.; Deigaard, S.L.; Rosenberg, J. Variations in Open and Laparoscopic Repair of Paediatric Inguinal Hernia. Dan. Med. J. 2020, 67, A12190687. [PubMed]

13. Schmedding, A.; Rolle, U. Decentralized Rather than Centralized Pediatric Surgery Care in Germany. Eur. J. Pediatr. Surg. 2017, 27, 399-406. [CrossRef]

14. DGKCH Kinderchirurgische Kliniken Und Praxen. Available online: https://www.dgkch.de/menu-kinderchirurgie-indeutschland/menu-kinderchirurgische-kliniken-praxen (accessed on 21 June 2020).

15. Institute for the Hospital Remuneration System (INEK). Available online: https:/ /www.g-drg.de/ (accessed on 30 January 2022).

16. Federal Joint Committee (G-BA). Quality Reports of the Hospitals—Federal Joint Committee (G-BA). Available online: https: //www.g-ba.de/themen/qualitaetssicherung/datenerhebung-zur-qualitaetssicherung/datenerhebung-qualitaetsbericht/ (accessed on 30 January 2022).

17. Federal Institute for Drugs and Medical Devices BfArM-ICD-10-GM. Available online: https://www.bfarm.de/EN/Codesystems /Classifications/ICD/ICD-10-GM/_node.html;jsessionid=5F02DD5528CD7BF691E6F56ADE7CEEEB.intranet372 (accessed on 30 January 2022).

18. Federal Institute for Drugs and Medical Devices BfArM-OPS. Available online: https://www.bfarm.de/EN/Code-systems/ Classifications/OPS-ICHI/OPS/_node.html (accessed on 30 January 2022).

19. Heydweiller, A.; Kurz, R.; Schröder, A.; Oetzmann von Sochaczewski, C. Inguinal Hernia Repair in Inpatient Children: A Nationwide Analysis of German Administrative Data. BMC Surg. 2021, 21, 372. [CrossRef]

20. Fujiogi, M.; Michihata, N.; Matsui, H.; Fushimi, K.; Yasunaga, H.; Fujishiro, J. Outcomes Following Laparoscopic versus Open Surgery for Pediatric Inguinal Hernia Repair: Analysis Using a National Inpatient Database in Japan. J. Pediatr. Surg. 2019, 54, 577-581. [CrossRef] 
21. Chan, Y.Y.; Durbin-Johnson, B.; Kurzrock, E.A. Pediatric Inguinal and Scrotal Surgery-Practice Patterns in U.S. Academic Centers. J. Pediatr. Surg. 2016, 51, 1786-1790. [CrossRef]

22. Dreuning, K.; Maat, S.; Twisk, J.; van Heurn, E.; Derikx, J. Laparoscopic versus Open Pediatric Inguinal Hernia Repair: State-ofthe-Art Comparison and Future Perspectives from a Meta-Analysis. Surg. Endosc. 2019, 33, 3177-3191. [CrossRef]

23. Nah, S.A.; Giacomello, L.; Eaton, S.; de Coppi, P.; Curry, J.I.; Drake, D.P.; Kiely, E.M.; Pierro, A. Surgical Repair of Incarcerated Inguinal Hernia in Children: Laparoscopic or Open? Eur. J. Pediatr. Surg. 2011, 21, 8-11. [CrossRef]

24. Kaya, M.; Hückstedt, T.; Schier, F. Laparoscopic Approach to Incarcerated Inguinal Hernia in Children. J. Pediatr. Surg. 2006, 41, 567-569. [CrossRef]

25. Takehara, H.; Yakabe, S.; Kameoka, K. Laparoscopic Percutaneous Extraperitoneal Closure for Inguinal Hernia in Children: Clinical Outcome of 972 Repairs Done in 3 Pediatric Surgical Institutions. J. Pediatr. Surg. 2006, 41, 1999-2003. [CrossRef]

26. Maat, S.; Dreuning, K.; Nordkamp, S.; van Gemert, W.; Twisk, J.; Visschers, R.; van Heurn, E.; Derikx, J. Comparison of Intra- and Extra-Corporeal Laparoscopic Hernia Repair in Children: A Systematic Review and Pooled Data-Analysis. J. Pediatr. Surg. 2021, 56, 1647-1656. [CrossRef]

27. Bruns, N.E.; Glenn, I.C.; McNinch, N.L.; Rosen, M.J.; Ponsky, T.A. Treatment of Routine Adolescent Inguinal Hernia Vastly Differs between Pediatric Surgeons and General Surgeons. Surg. Endosc. 2017, 31, 912-916. [CrossRef] [PubMed]

28. Lobe, T.E.; Bianco, F.M. Adolescent Inguinal Hernia Repair: A Review of the Literature and Recommendations for Selective Management. Hernia J. Hernias Abdom. Wall Surg. 2022. [CrossRef] [PubMed]

29. Yoshimura, S.; Migita, M.; Matsufuji, H. The Clinical Outcomes of Pediatric Inguinal Hernia Repairs Operated by Surgical Residents. Asian J. Surg. 2020, 43, 730-734. [CrossRef] [PubMed]

30. Shibuya, S.; Fujiwara, N.; Ochi, T.; Wada, M.; Takahashi, T.; Lee, K.D.; Miyazaki, E. The Learning Curve of Laparoscopic Percutaneous Extraperitoneal Closure (LPEC) for Inguinal Hernia: Protocoled Training in a Single Center for Six Pediatric Surgical Trainees. BMC Surg. 2019, 19, 6. [CrossRef] 